\title{
ABUNDANCE, RICHNESS AND ROOT COLONIZATION OF ARBUSCULAR MYCORRHIZAL FUNGI IN NATURAL AND SEMI-NATURAL LANDUSE TYPES AT UPPER HANTANA
}

\author{
Fathima Mafaziya ${ }^{1}$ and Sumedha Madawala ${ }^{2 *}$ \\ ${ }^{1}$ Department of Zoology, Faculty of Science, University of Peradeniya, Sri Lanka. \\ ${ }^{2}$ Department of Botany, Faculty of Science, University of Peradeniya, Peradeniya, Sri Lanka. \\ Accepted June 23, 2015
}

\begin{abstract}
There is a scarcity of published information on the abundance and richness of arbuscular mycorrhizal fungi (AMF) in natural and semi-natural landuse types in Sri Lanka. The Upper Hantana (UH) area, which comprises landuse types with different histories, was selected to fulfill this knowledge gap. A study was carried out to investigate the abundance and richness of AMF in selected landuse types, including restored pine stand (REP), degraded grassland (DEG), Paraserianthes stand (PST) and natural forest patch (NFP) at Upper Hantana in the Central Province of Sri Lanka. The highest AMF spore abundance was observed in the NFP. However, the AMF spore richness was higher in both NFP and REP than in DEG and PST. At NFP, the medium-sized spores dominate the AMF spore population. Furthermore, NFP showed the least evenness in AMF distribution compared to other landuse types. Glomus was the most abundant genus in all selected landuse types. Acaulospora was observed only in DEG and PST. The colonization potential of AMF varies highly between species and selected landuse types, with no clear relationship between AMF abundance and root colonization potential. The results speculate that AMF spore abundance is determined by the composition and diversity of the vegetation. The results also revealed that the AMF richness at REP was similar to that of NFP, indicating a positive impact on the below-ground biota within a relatively short period following restoration.
\end{abstract}

Keywords: arbuscular mycorrhizal fungi, restoration, landuse types, Paraserianthes stand, restored Pine stand, grassland, natural forest

\section{INTRODUCTION}

Mycorrhizae are highly evolved, mutualistic associations between a group of fungi and plant roots. Arbuscular mycorrhizal fungi (AMF) reported to have a widespread occurrence in the plant kingdom with many benefits to plant growth (Janos 1980; Wolfe and Klinomus 2005; Smith and Read 2008; Lee et al., 2013). In this highly specialized relationship, the host receives mineral nutrients while the fungus obtains photosynthate s(Harley and Smith 1983; Harley 1989). AMF play an important role in plant growth especially under nutrient poor conditions. Due to nonspecific host specificity, AMF influence not only a single plant species but populations (Lee et al., 2013; Leake et al., 2004). There is evidence to suggest that differences in community composition of AMF play a potential role in plant diversity and ecosystem functions (Van der Heijden et al., 1998). Therefore, the knowledge on the diversity of AMF and their colonization potentials are considered important information to assess the health of an ecosystem and allows comparisons between different ecosystems (Jeffries et al., 2003; Lee et al., 2013).
Ecologists have recognized the importance of AM fungi in restoration of ecosystems for decades (Reeves et al., 1979; Allen 1984; Miller 1987; Koziol and Bever, 2015). AMF play a crucial role in the reclamation and restoration of degraded ecosystems and mycorrhizal-dependent species could act as promising candidates in reforestation programs (Cuenca et al., 1998). Therefore, the knowledge on the diversity and colonization potentials of AMF may provide additional insight in conservation biology and environmental protection.

Changes in existing landuse types may alter the below-ground ecosystem, which often can lead to loss of soil microbial biodiversity and depletion of soil carbon (Doran and Zeiss 2000). The soil quality may change along with the conversion of diverse forests into monoculture plantations or grasslands(Thomson et al., 2009). However, the impacts of land use changes on AMF communities are not explored extensively (Oehl et al., 2010). Understanding the mycorrhizal responses to anthropogenic changes may help predicting paths of the future communities and ecosystems ( $\mathrm{Hu}$ et al., 2013; Yang et al., 2013).

*Corresponding author's email: sumedha.madawala@gmail.com 
The Upper Hantana (UH), the focal area of the present study, is an important yet severely threatened ecosystem. The land at UH is cleared for tea in early $19^{\text {th }}$ century and some of these tea plantations were later abandoned. These abandoned lands were gradually converted into grass-dominated habitats. The grasslands at UH are highly degraded and marginal due to high soil erosion and frequent fires during dry spells. In the 1980s, plantations of Pinus and Paraserianthes were introduced to replace degraded grasslands at UH (Ambagahaduwa et al., 2009). At present, grasslands, few remnants of natural forest, regenerating semi-natural forests (broad-leaved forests dominated by Alstonia and Paraserianthes) and Pinus plantations dominate the landscape. The present study was conducted with the aim of assessing the status of AMF abundance, composition and richness in selected semi-natural landuse types in $\mathrm{UH}$ and compared that with a natural forest patch in the area.

\section{MATERIALS AND METHODS}

\section{Study site}

The Hantana range, which falls in the agroecological region of wet zone, mid country (WM3), is located in the Central Province of Sri Lanka. The elevation ranges from $518 \mathrm{~m}-1,100 \mathrm{~m}$ and is underlain by pre-cambrian metamorphic rocks of the Highland Series (Mapa et al., 1999). The major soil group is Red Yellow Podzolic or ultisols according to USDA classification (Panabokke 1996). The mean annual precipitation and temperature are $2,131 \mathrm{~mm}$ and 24.1 ${ }^{\circ} \mathrm{C}$, respectively. The rainfall is received from both north-east and south-west monsoons and distributed more or less evenly throughout the year.

A small remnant of the natural forest still remain at a higher elevation level, which supposedly represents the original forest cover at UH before the clearance for tea during the colonial era. Degraded grassland (DEG), natural forest patch (NFP), Paraserianthes stand (PST) and restored pine stand (REP) were selected to conduct the present study (Table 1).

\section{Soil sampling and root extraction}

From two representative plots from each landuse type, 10 soil samples (each soil sample is a composite of 5 soil samples) were collected ( 5 from each) from a depth of 0-20 cm using a hand-held soil corer. All 10 samples from each landuse type were used as replicates for the spore count, while 6 randomly selected samples (from each landuse type) were used in the analysis of soil parameters (soil $\mathrm{pH}$ and moisture). Soil samples were collected in ziplock polythene bags, and were brought to the laboratory and stored at $4^{\circ} \mathrm{C}$ until analyses.

Five most common herbaceous and tree (seedlings) species in the undergrowth of each landuse types were identified and their root samples were extracted to assess the colonization potential of AM fungi. From each species, 5-6 plants were randomly selected to extract roots. The extracted root samples were washed thoroughly under running water to remove any soil particles and other organic debris, and stored in $50 \%$ ethanol until determination of the percentage root colonization.

Table 1.The historical background and the present vegetation of the selected study sites at Upper Hantana, Sri Lanka; degraded grassland (DEG), Paraserianthes stand (PST), restored pine stand (REP) and the natural forest patch (NFP).

\begin{tabular}{|c|c|c|c|c|}
\hline & $\begin{array}{l}\text { Degraded } \\
\text { grassland (DEG) }\end{array}$ & $\begin{array}{l}\text { Paraserianthes } \\
\text { stand(PST) }\end{array}$ & $\begin{array}{l}\text { Restored Pine stand } \\
\text { (REP) }\end{array}$ & $\begin{array}{l}\text { Natural Forest } \\
\text { Patch } \\
(\text { NFP) }\end{array}$ \\
\hline History & $\begin{array}{l}\text { Abandoned } \\
\text { tea/coffee } \\
\text { plantations later } \\
\text { converted into } \\
\text { grasslands }\end{array}$ & $\begin{array}{l}\text { Paraserianthes } \\
\text { was introduced into } \\
\text { degraded } \\
\text { grasslands in 1980s } \\
\text { by the Forest } \\
\text { Department }\end{array}$ & $\begin{array}{l}\text { Some pine (Pinus } \\
\text { caribaea) stands } \\
\text { were restored in } \\
2003 \text { by } \\
\text { introducing } \\
\text { broadleaved } \\
\text { species }\end{array}$ & $\begin{array}{l}\text { Remaining natural } \\
\text { forest patch with } \\
\text { minimum } \\
\text { disturbances }\end{array}$ \\
\hline Present vegetation & $\begin{array}{l}\text { Panicum } \\
\text { maximum- } \\
\text { dominated } \\
\text { grassland }\end{array}$ & $\begin{array}{l}\text { Paraserianthes } \\
\text { falcataria } \\
\text { dominated } \\
\text { vegetation }\end{array}$ & $\begin{array}{l}\text { Broad-leaved } \\
\text { species including } \\
\text { Terminalia } \\
\text { bellirica, Maduca } \\
\text { fulva, Michelia } \\
\text { champaca, } \\
\text { Artocarpus nobilis } \\
\text { etc. }\end{array}$ & Natural forest \\
\hline
\end{tabular}


Separation and identification of spores

A $100 \mathrm{~g}$ soil from each sample (10 soil samples from each landuse type separately) was used for spore extraction by wet sieving decanting method as described by Brundrett et al., (1996). The material retained on 125,63 and $45 \mu \mathrm{m}$ sieves was collected on glass fiber filter papers separately (Whatman GF/A) and AMF spores and sporocarps were counted and differentiated into morphotypes under reflected light on stereomicroscope (Olympus SZ $61)$. Spores from each morphotype were mounted on permanent slides using Melzer's reagent and observed under a bionucular light microscope (Oympus CX 21) at $\times 400$ magnification and identified in to generic level based on the descriptions given in the International Culture Collection of Arbuscular and Vesicular-Arbuscular Mycorrhizal Fungi (INVAM, West Virginia, USA; http://invam.caf.wvu.edu).

\section{AMF root colonization assessment}

Roots were cleared in a water bath by heating with $10 \%(\mathrm{w} / \mathrm{v}) \mathrm{KOH}$ at $60-90^{\circ} \mathrm{C}$ for 1 hour. Once cleared, a few drops of Chlorazol Black E (CBE) solution was added and heated again for about 20 minutes to several hours (until the root samples were stained properly) at $90^{\circ} \mathrm{C}$. The excess stain was then washed off, acidified with $1 \% \mathrm{HCl}$ solution before mounting roots on a glass slide with few drops of 50\% Glycerol (Kormanick and McGraw 1982; Brundrett et al., 1994 and 1996). The colonization percentage was calculated using the grid-intersect method after McGonigle et al., (1990) by scoring root intersects that contained different AM fungal structures (spores, hyphae and arbuscules) at $\times 100$ magnification.

\section{Preparation of trap cultures}

Maize (Zea mays) seeds were sown (3 seeds per pot) in plastic pots (with a diameter of $15 \mathrm{~cm}$ ) containing a mixture of potting medium [autoclaved garden soil and coarse sand mixed in 1:1 (v/v) ratio] and $50 \mathrm{~g}$ of composite field-fresh soil taken from each landuse type as an inoculum of AMF spores. For each landuse type, there were 6 replicate pots. Plants were raised in a glasshouse for three to four months.
Spores were extracted from the pots using wet sieving and decanting method as mentioned previously (Brundrett et al.,1996). Spore morphotypes were identified and counted.

\section{Data analysis}

One-way ANOVA was carried out to compare the density and richness of AMF spores $(n=10)$ between landuse types. The General Linear Model (GLM) was carried out to compare spore abundance and richness with spore size classes and landuse types as random factors. Mean separations were done using Tukey's test at the 0.05 level of significance. All data were checked for normality using Anderson-Darling test to meet ANOVA assumptions. All statistical analyses were performed using Minitab (version 16.0) software.

\section{RESULTS}

\section{Soil parameters}

All landuse types showed acidic soil $\mathrm{pH}$ irrespective of their different vegetation cover and histories. The natural forest patch (NFP) showed the lowest soil $\mathrm{pH}$ compared to other landuse types, REP, DEG and PST. However, DEG and PST showed significantly higher soil $\mathrm{pH}$ than that of REP. As expected, the soil moisture was highest $(\approx 43 \%)$ in the NFP compared to other three semi-natural landuse types (19, 20 and $22 \%$ DEG, PST and REP, respectively) (Table 2).

\section{Spore abundance and richness}

The highest total number of AMF spores were recorded from soil samples taken from the natural forest patch (NFP) while the lowest was recorded from the Paraserianthes stand (PST) (Table 3; 8,234 and 1,573 respectively). The restored pine stand (REP) had the second highest AMF spore numbers $(3,991)$ followed by DEG $(1,920)$. Highest number of spore morphotypes was also recorded from NFP (20) and the lowest (14) from the degraded grassland (DEG). In AMF richness too, REP came second only to NFP with 18 spore morphotypes (Table 3 ).

Table 2.Soil $\mathrm{pH}$ (soil:distilled water in 1:3 ratio) and gravimetric moisture content (\%) of the study sites $(\mathrm{n}=6)$, restored pine (REP), degraded grassland (DEG), natural forest patch (NFP) and Paraserianthes stand (PST) at Upper Hanatna, Sri Lanka. The significant differences are highlighted using different superscript letters after one-way ANOVA $(\mathrm{F}=58.7, \mathrm{p} \leq 0.001$ and $\mathrm{F}=92.5, \mathrm{p} \leq 0.001$ for soil $\mathrm{pH}$ and soil moisture contents, respectively).

\begin{tabular}{lllll}
\hline & $\begin{array}{l}\text { Restored Pine } \\
(\mathrm{REP})\end{array}$ & $\begin{array}{l}\text { Degraded grassland } \\
(\mathrm{DEG})\end{array}$ & $\begin{array}{l}\text { Natural Forest } \\
\text { Patch (NFP) }\end{array}$ & $\begin{array}{l}\text { Paraserianthes } \\
\text { stand (PST) }\end{array}$ \\
\hline Soil pH & $5.23^{\mathrm{b}}$ & $6.13^{\mathrm{a}}$ & $4.86^{\mathrm{c}}$ & $6.21^{\mathrm{a}}$ \\
Soil Moisture (\%) & $21.6^{\mathrm{b}}$ & $18.7^{\mathrm{b}}$ & $42.6^{\mathrm{a}}$ & $19.5^{\mathrm{b}}$ \\
\hline
\end{tabular}


Table 3.Total number of AMF spores, morphotypes, Shannon Diversity index and evenness values of the four land use types at Upper Hantana, restored Pinus stand (REP), Paraserianthes stand (PST), degraded grassland (DEG) and Natural forest patch (NFP).

\begin{tabular}{lcccc}
\hline Land use type & $\begin{array}{c}\text { Total number of } \\
\text { AMF Spores (per } \\
\text { kg of fresh soil) }\end{array}$ & $\begin{array}{c}\text { Total number of } \\
\text { spore morphotypes } \\
\text { (per kg of fresh } \\
\text { soil) }\end{array}$ & $\begin{array}{c}\text { Shannon } \\
\text { Diversity Index } \\
\left(H^{\prime}\right)\end{array}$ & Evenness \\
\hline REP & 3,991 & 18 & 2.28 & 0.79 \\
PST & 1,573 & 16 & 2.14 & 0.77 \\
DEG & 1,920 & 14 & 2.17 & 0.82 \\
NFP & 8,234 & 20 & 2.44 & 0.12 \\
\hline
\end{tabular}

Table 4.Number of spore morphotypes belonging to different genera in four different landuse types at Upper Hantana, Sri Lanka; restored Pinus stand (REP), Paraserianthes stand (PST), degraded grassland (DEG) and Natural forest patch (NFP).

\begin{tabular}{lllll}
\hline & $\begin{array}{l}\text { Restored Pine } \\
\text { (REP) }\end{array}$ & $\begin{array}{l}\text { Degraded } \\
\text { grassland (DEG) }\end{array}$ & $\begin{array}{l}\text { Natural Forest } \\
\text { Patch (NFP) }\end{array}$ & $\begin{array}{l}\text { Paraserianthes } \\
\text { stand (PST) }\end{array}$ \\
\hline Glomus & 7 & 2 & 10 & 5 \\
Gigaspora & 2 & - & 2 & - \\
Acaulospora & - & 3 & - & 3 \\
Scutellospora & - & 1 & 2 & - \\
Unidentified & 9 & 8 & 6 & 8 \\
\hline $\begin{array}{l}\text { Total Number of } \\
\text { morphotypes }\end{array}$ & 18 & 14 & 20 & 16 \\
\hline
\end{tabular}

According to the calculated Shannon-Weiner Diversity indices, NFP showed the highest AMF spore diversity while PST the lowest (Table 3). In spite of having the highest AMF diversity, NFP showed the lowest evenness value compared to other landuse types.

In all landuse types, 30 to $50 \%$ of the spore morphotypes were not identified into their generic levels. Glomus was recorded in all landuse types (Table 4). Acaulospora only observed in DEG and PST landuse types, while Scutellospora located only in DEG and NFP. Gigaspora found in both REP and NFP landuse types (Figure 1).

In the trap culture experiment, a total of 16, 12, 10 and 11 morphotypes were identified from landuse types, NFP, DEG, REP and PST, respectively. In consistent with the AMF spore morphotypes recorded from field soils, NFP has recorded the highest AMF richness than the rest of the study sites. Morphotypes belonging to Glomus species were recorded in all landuse types while Scutellospora species was only recorded in DEG suggesting its rarity and specificity. No new morphotypes were recorded from the trap culture experiment.

The average number of AMF spore morphotypes (richness) was significantly higher in NFP and REP than that of PST and DEG (Figure 2). However, the average density of AMF spores showed somewhat different results to richness values. The
NFP recorded the highest spore density value (at $\mathrm{p} \leq$ $0.001)$ compared to the rest of the landuse types (REP, PST and DEG).

Distribution of differently-sized AMF spore morphotypes in each landuse type showed variations in richness and abundance among sites (Figures 3 and 4). However, the results showed no apparent trend in the distribution of differently-sized spore morphotypes among landuse types. At REP, the richness of medium-sized (63-125 $\mu \mathrm{m})$ spore morphotypes was higher than that of small- and large-sized spore morphotypes. The medium-sized AMF spores dominate the total spore count in the natural forest patch (NFP) compared to other landuse types (Figure 4). In RFP, the density of large spores $(>125 \mu \mathrm{m})$ was significantly the lowest compared to other 2 size classes (small and medium), while in DEG and PST, the AMF spore densities belonging to different size classes did not show any significant differences (Figure 4).

\section{Root colonization}

The overall root colonization of AMF was relatively low in all landuse types with averages of 16.4, 15.4, 7.6 and $7.3 \%$ in REP, DEG, NFP and PST, respectively (Table 5). Even within a landuse type, the percentage root colonization varied among species with values ranging from $4-51 \%$ in REP, 7$20 \%$ in DEG and $2-12 \%$ in NFP and PST sites. The highest root colonization was recorded from a perennial climber known as Asparagus racemosus in REP. 


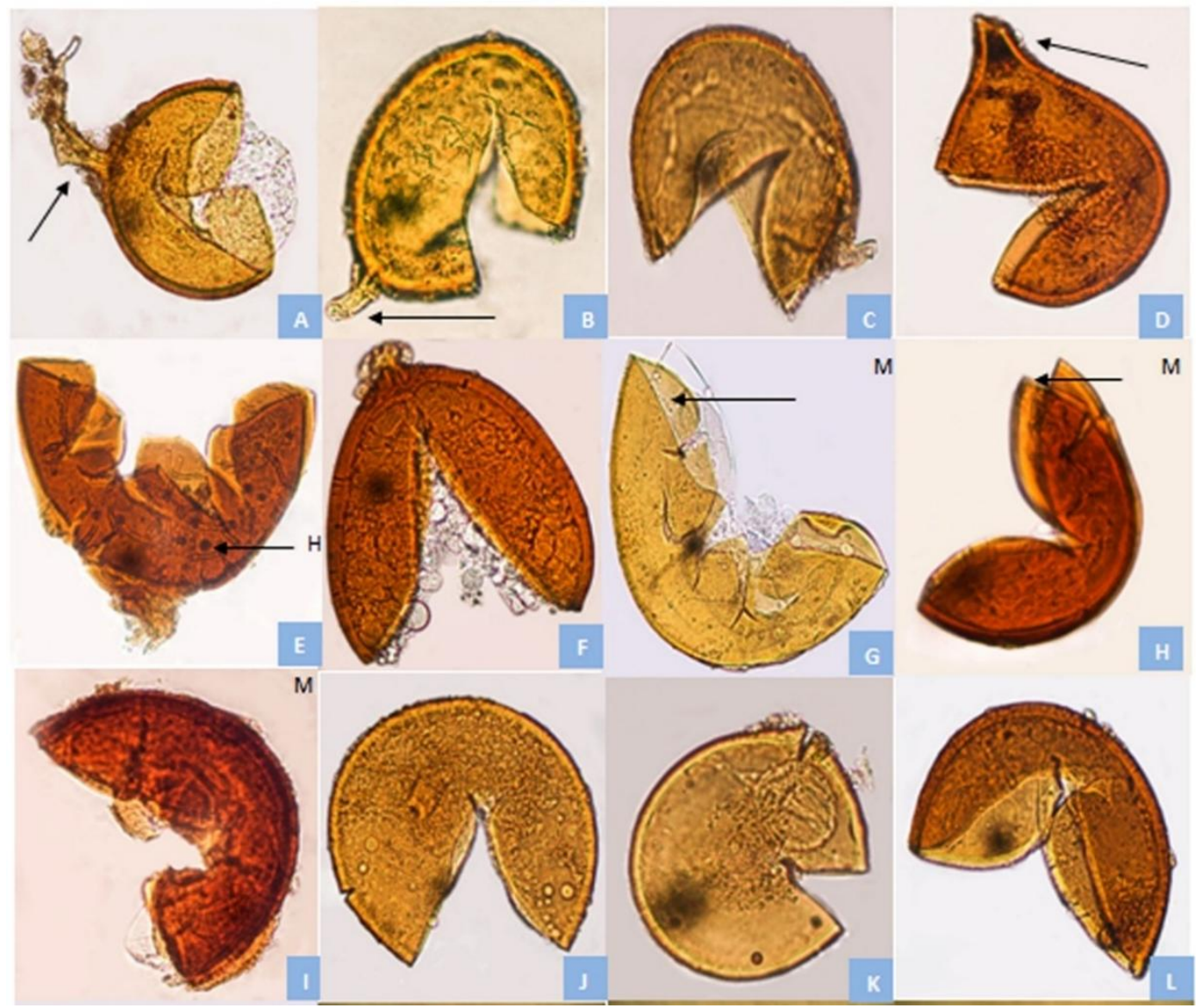

Figure 1. Photographs showing AMF spores belong to Glomus, Gigaspora, Scutellospora and Acaulospora species. Spore wall characteristics and developmental and germination stages of AMF spores were highlighted. A-M photos were taken from an Olympus BX 52 (at x400 magnification) microscope while N-O was taken using a Polarizing microscope (Euromex).Abbreviations: $\mathrm{H}=$ subtending hypha, $\mathrm{S}=$ stalk. A-D: Glomus species (A. Young spore of the Glomus sp. from REP, squashed to show spore contents found in young spores, the thick brown unit wall and subtending hyphal attachment can be seen; D. Squashed spore of another Glomus morphotype stained with Melzer's reagent. A stalk can be seen; E: Squashed spore of Gigaspora sp. with a swollen subtending hyphae; F: Crushed spore of Scutellospora sp. stained with Melzer's reagent. G-H: Acaulospora spores; G: Squashed Acaulospora spore showing inner layers; H: Squashed Acaulospora spore; I: Glomus sp.; J: Scutellospora sp.; K, L: unidentified morphotypes.
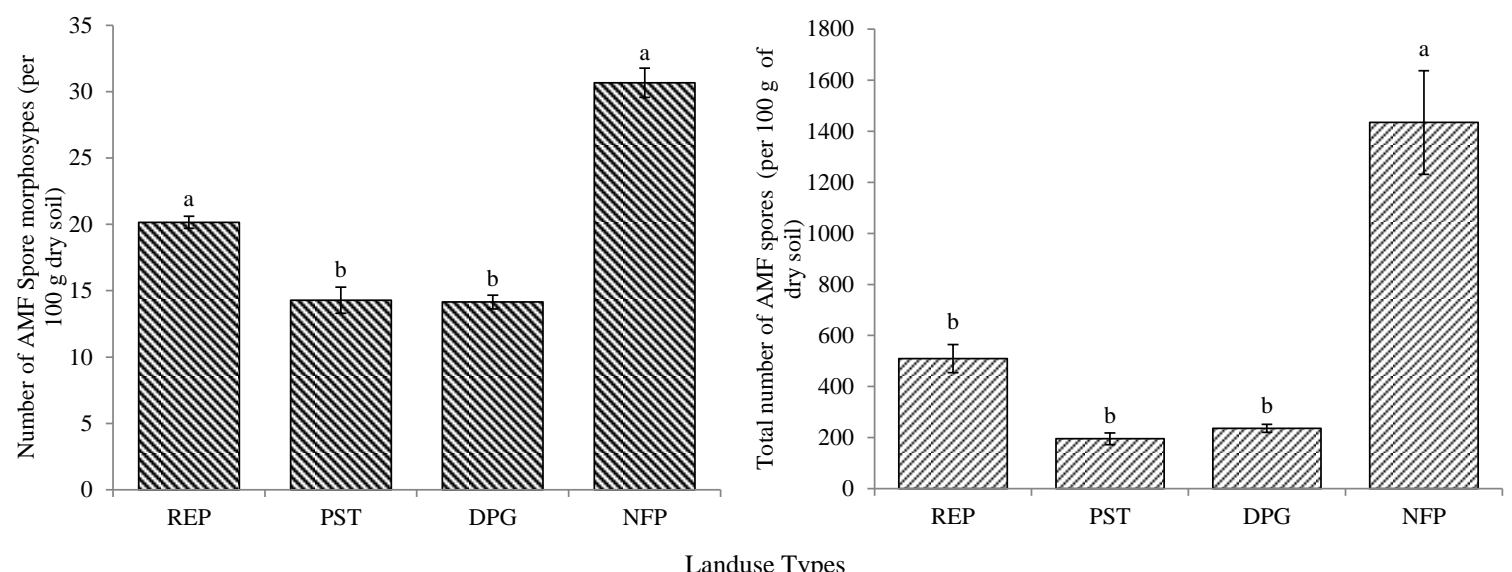

Figure 2. Number of AMF morphotypes and AMF spores (per $100 \mathrm{~g}$ of dry soil) in different landuse types restored pine stand, Paraserianthes stand, degraded grassland and natural forest patch (REP, PST, DEG and NFP respectively) in Upper Hantana, Kandy, Sri Lanka. Vertical bars represent standard error of the mean $(n=$ 10). Different letters indicate significant differences between landuse types after one-way ANOVA (Richness: $\mathrm{F}=31.94, \mathrm{p} \leq 0.001$; density: $\mathrm{F}=15.46, \mathrm{p} \leq 0.001$ ). 


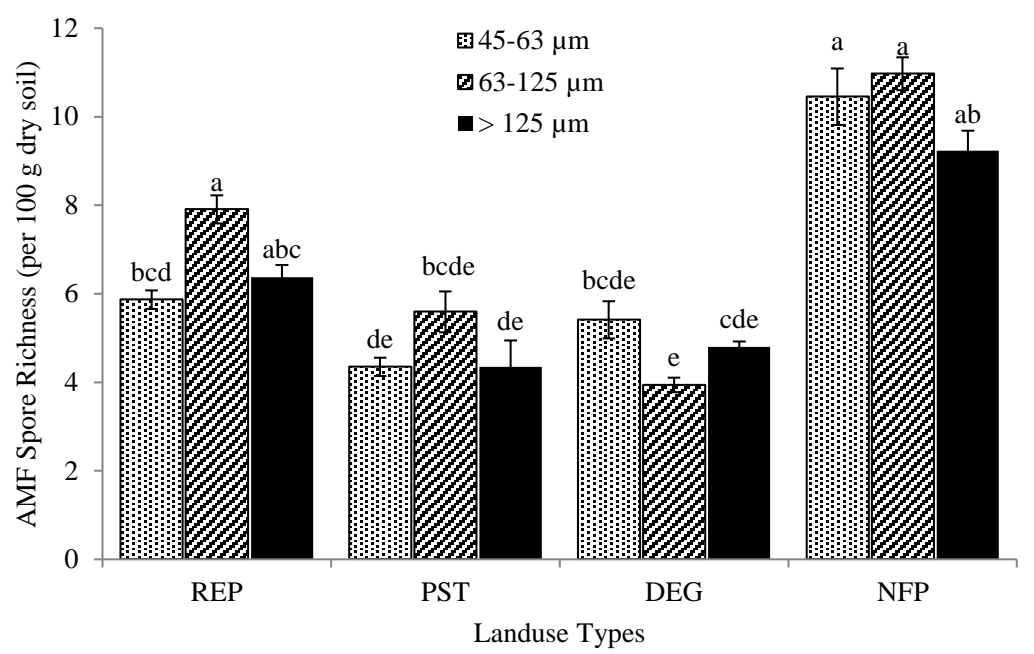

Figure 3. Average richness of AMF spores (per $100 \mathrm{~g}$ dry soil) belonged to different size classes (45-63, 63-125 and $>125 \mu \mathrm{m}$ ) in four different landuse types; Restored Pinus Stand (REP), Paraserianthes stand (PST), degraded Grassland (DEG) and Natural Forest Patch at Upper Hantana area, Sri Lanka. Error bars indicate the standard error of the mean value (SEM). Different letters indicate significant differences after GLM analysis followed by Tukey's test at $\mathrm{p} \leq 0.5(\mathrm{n}=10)$.

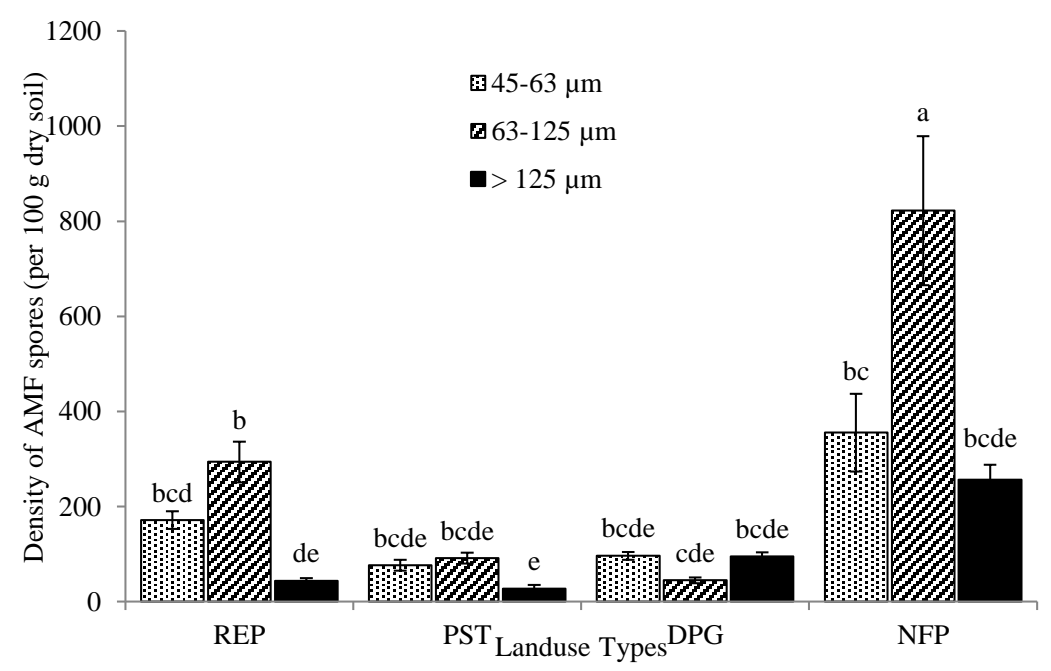

Figure 4. Average density of AMF spores (per $100 \mathrm{~g}$ dry soil) belonged to different size classes (45-63, 63-125 and $>125 \mu \mathrm{m}$ ) in four different landuse types; Restored Pinus Stand (REP), Paraserianthes stand (PST), degraded Grassland (DEG) and Natural Forest Patch at Upper Hantana area, Sri Lanka. Error bars indicate the standard error of the mean value (SEM). Different letters indicate significant differences after GLM analysis followed by Tukey's test at $\mathrm{p} \leq 0.5(\mathrm{n}=10)$.

Furthermore, Clidemia hirta, a known invader in the wet zone forest undergrowth, showed diverse levels of AMF colonization in different landuse types with values ranging from 18, 13 and 9\% in DPG, REP and NFP, respectively.

\section{DISCUSSION}

Spore quantification is used as a tangible method in enumerating the abundance and richness of AMF, since spores are highly resistant to adverse environmental conditions (Abbott and Robson
1991). However, early studies suggested that AMF spore abundance do not directly reflect the colonizing potential of plant roots (Clapp et al., 1995). Nevertheless, due to high costs of other molecular methods, AMF spore counts and their identification into morphotypes (if possible even into species) remain as a more economical, fast and feasible method of studying AMF (Douds and Millner 1999; Oehl et al.,2010). The present results revealed that the AMF communities were quite distinct among study sites possibly due to contrasting landuse types and micro-climatic conditions prevailing in these habitats. 
Table 5. Percentage root colonization of AM fungi in representative plant species from different landuse types (DEG, NFP, PST and REP) at Upper Hantana Area, Kandy, Sri Lanka.

\begin{tabular}{|c|c|c|}
\hline Plant species & Family & $\%$ root colonization \\
\hline \multicolumn{3}{|l|}{ Degraded Grassland (DEG) } \\
\hline Axonopus compresses & Poaceae & 20.0 \\
\hline Panicum maximum & Poaceae & 15.3 \\
\hline Eupatorium odoratum & Asteraceae & 16.8 \\
\hline Mimosa pudica & Fabaceae & 7.3 \\
\hline Clidemia hirta & Melastomataceae & 17.8 \\
\hline \multicolumn{3}{|l|}{ Natural Forest Patch (NFP) } \\
\hline Panicum maximum & Poaceae & 11.6 \\
\hline Tithonia diversifolia & Asteraceae & 6.7 \\
\hline Panicum maximum & Poaceae & 7.6 \\
\hline Mimosa pudica & Fabaceae & 2.1 \\
\hline Clidemia hirta & Melastomataceae & 8.9 \\
\hline \multicolumn{3}{|l|}{ Paraserianthes stand (PST) } \\
\hline Paraserianthes $s p$. & Fabaceae & 12.0 \\
\hline Eleutheranthera ruderalis & Asteraceae & 10.3 \\
\hline Mimosa pudica & Fabaceae & 5.4 \\
\hline Vernonia cinerea & Asteraceae & nd \\
\hline Ageratum conyzoides & Asteraceae & 2.0 \\
\hline \multicolumn{3}{|l|}{ Restored Pine stand (REP) } \\
\hline Panicum maximum & Poaceae & 11.2 \\
\hline Piper longum & Piperaceae & 4.3 \\
\hline Asparagus racemosus & Liliaceae & 50.7 \\
\hline Tithonia diversifolia & Asteraceae & 4.2 \\
\hline Clidemia hirta & Melastomataceae & 12.5 \\
\hline
\end{tabular}

The highest AMF diversity was observed in the natural forest patch (NFP) $\left(\mathrm{H}^{\prime}=2.44\right)$, which was closely followed by the restored pine stand (REP) $\left(H^{\prime}=2.28\right)$. The basic soil parameters showed that NFP has the lowest $\mathrm{pH}$ and the highest soil moisture content among the study sites (Table 1).

According to Clark (1997), some AM fungal species from genera, Acaulospora, Gigaspora, and Glomus are more tolerant of acidic conditions. Previous studies have shown a close relationship between the diversity of AMF and the diversity of plant communities, suggesting AMF play a critical role in competitive interactions among plants (Streitwolf et al., 1997; Van der Heijden et al., 1998). Relatively higher AMF diversity and richness at REP compared to DEG and PST indicated that REP showed an encouraging trajectory in terms of invigorating the soil health after a period of 11 years since the restoration of the site using broad-leaved native species. Due to low ecological value of monospecific Pinus plantations, the conversion of pine stands into some form of forest cover is highly recommended. The present results support the idea that AMF could play an important role in restoring the soil health which will positively influence the growth and composition of the vegetation.
Glomus was the most frequent and abundant AMF genus in all three landuse types except in DEG. Since Glomus is a well-known host generalist, it has the potential to colonize a range of plants. Glomus is known to occur in extremely broad range of habitats with high tolerance of environmental factors (Börstler et al., 2008). PST is located somewhat at a higher elevation than that of REP and DEG and therefore the land is prone to erosion. Small-scale earth slips were often evident in the study site. Furthermore, the forest floor of the PST was comparatively barren with very little undergrowth. The reduced AMF spore density at PST can be explained by these frequent disturbances in the habitat which could influence soil fungal populations negatively through lack of surface organic matter on which these obligate symbionts depend on for their carbon source. Studies also revealed that forest disturbances cause negative effects on soil microorganisms, reducing the diversity and composition of AMF (Allen et al., 1995). All these factors may have led to low AMF abundance and richness in PST. Janos (1980) also pointed out that AMF spores can be washed down with rain water to lower slopes influencing a heterogeneous distribution in sloping landscape. However, in the present study elevation was not considered as a 
factor and therefore the relationship between abundance and richness of AMF spores with that of the elevation could not be established.

The results also reported a lower abundance of AMF spores in DEG where grasses dominate the vegetation with occasional herbaceous species. In contrast to present findings, others observed almost similar and sometimes even higher abundance of AMF spores in grass-dominated habitats over tropical forests in studies carried out in Nicaragua, Costa Rica and Brazil (Picone 2000; Zangaro et al., 2013). According to them, this higher abundance of AMF spores in grasslands over tropical forests was possibly due to higher turn-over rates of fine roots and soil $\mathrm{pH}$ in grasslands than in mature forests. In the present study, the highest spore abundance was observed in the NFP suggesting that the plant diversity and richness may play a critical role in deciding the abundance and diversity of AMF in spite of low fine root turn-over rates in mature forest trees. The natural forest patch consists of dense vegetation with comparatively rich undergrowth with no symptoms of erosion or any other anthropogenic disturbances. Börstler et al. (2008) observed higher AMF colonization and abundance in un-disturbed lands than that of disturbed lands suggesting that soil disturbances due to natural and anthropogenic activities often affect negatively on AMF population. Other studies too have shown that the AMF population, species richness, and root colonization are often reduced by soil disturbances (Helgason et al., 1998; Oehl et al.. 2010).

After years of enrichment with native species, REP seems to have restored its AMF richness to a level which is comparable to the undisturbed forest patch located nearby. The two main processes that control the population of AMF following disturbances are known to be immigration of new propagules from nearby areas and survival of residual propagules (Warner et al., 1987). We tested soil samples of the un-restored pine stand for AMF spores but came up with negative results. Pinus is a known to form associations with ectomycorrhizal species. Therefore, we could speculate that AM fungal spores in the REP have introduced mainly through immigration. Introduction of AMF spores through infected native plant seedlings/saplings is also considered as a likely option during restoration interventions. This improved AMF population may be a direct consequence of land conversion from a mono-specific pine stand into a multi-species vegetation. However, in spite of increased AMF spore richness in REP, the abundance remained almost similar to other two study sites, DEG and PST. The comparatively low abundance of AMF spores at REP is perhaps due to its status as a relatively new habitat for AMF.

Arbuscular mycorrhizal root colonization of different structures varied among plant species both within and between landuse types. The percentage root colonization of Panicum maximum was 15.3, 11.6 and $11.2 \%$ in DEG, NFP and REP, while Clidemia hirta has shown colonization percentages of $17.8,12.5$ and $8.9 \%$ in DEG, REP and NFP, respectively. The results indicate that both plant species have shown higher root colonization potential in DEG where soil nutrients may be the most limiting. Furthermore, DEG showed lower richness and abundance of AMF spores compared to other study sites. However, early studies reported that there is no positive relationship between root colonization and species richness (Fisher and Vovoides 2004). Furthermore, Asparagus racemosus in REP had the highest percentage root colonization $(50.7 \%)$ out of all plant species examined across all land use types. This plant species itself may have contributed largely to the increased abundance of AMF at REP. Overall, the AMF colonization was rather low in all landuse types. This was perhaps due to higher phosphorus levels in soil which could inhibit the development and colonization of AMF (Abbott and Robson, 1984). According to previous studies, AMF colonization by roots is influenced by several factors including soil properties, soil water content, plant phenology, predation and propagule availability (Anderson et al., 1984; Johnson et al., 1991; Anderson et al., 1994; Schultz et al., 2001; Muthukumar et al., 2003). Others suggested that AMF spore abundance do not always correlate with root colonization potential of AMF (Camargo-Ricalde and Dhilion 2003). In favour of the present findings, Daniell et al. (2001) stressed that the level of spore production does not reflect the abundance of AMF in roots. The present results speculated that plants growing in resource poor conditions rely on AMF more than the species growing under high resource availability. Though, changes in AMF colonization across landscape can be influenced by microsite differences (Reynolds et al., 2003), the present studydid not adequately address that issue as the main focus was to assess the levels of AMF richness and abundance in different natural and semi-natural landuse types.

In conclusion, results showed that AMF abundance and richness vary among natural and semi-natural landuse types greatly. The restored pine stand attained a level (in terms of AMF richness) which is comparable to the natural forest patch, indicating a positive role of restoration since its initiation in 2003. In spite of higher richness of AMF, the REP had lower AMF abundance than that of NFP indicating a slower attainment of AMF population comparable to the natural forest patch (NFP). However, AMF richness and abundance seem to determine by the richness and the diversity of the existing vegetation indicating its overriding effect on AMF than the fine root turn-over rates as suggested by previous workers. 
The results suggest that the vegetation cover and disturbances due to natural and anthropogenic factors may play a role in determining the abundance and richness of AMF spores. However, the colonization potential of roots does not reflect the abundance and richness of AMF spores in soil. Restoration strategies not only enhance the composition and diversity of the vegetation, but also the abundance and richness of AMF.

\section{REFERENCES}

Abbott, L.K. and Robson, A.D. 1991. Factors influencing the occurrence of vesiculararbuscular mycorrhizas. Agriculture, Ecosystems and Environment 35: 121-150.

Allen, E.B. 1984. VA mycorrhizae and colonizing annuals: implications for growth, competition, and succession. Pages $42-52$ in S. E. Williams, and M. F. Allen, (eds.) VA mycorrhizae and reclamation of arid and semi-arid lands. University of Wyoming Agricultural Experiment Station, Laramie.

Allen, E.B., Allen, M.F., Helm, D.J., Trappe, J.M., Molina, R. and Rincon, E. 1995. Patterns and regulation of mycorrhizal plant and fungal diversity. Plant and Soil 170: 47-62.

Ambagahaduwa, I.M., Prasad, N., Gunatilleke, I.A.U.N., Seneviratne, G. and Gunatilleke, C.V.S. 2009. Estimation of above ground biomass of a Pinus caribaea Morelet stand in lower Hantana. Journal of National Science Foundation 37(3): 195-201.

Anderson, M.C., Hetrick, B.A.D. and Wilson, G.W.T. 1994. Mycorrhizal dependence of Andropogon gerardii and Schizachyrium scoparium in Two Prairie Soils. The American Midland Naturalist 132(2): 366-376.

Anderson, R.C., Liberta, A.E. and Dickman, L.A. 1984. Interaction of vascular plants and vesicular arbuscular mycorrhizal fungi across a soil moisture gradient. Oecologia 64: 111-117.

Börstler, B., Raab, P.A., Thiery, O., Morton, J.B. and Redecker, D. 2008. Genetic diversity of the arbuscular mycorrhizal fungus Glomus intraradices as determined by mitochondrial large subunit rRNA gene sequences is considerably higher than previously expected. New Phytologist 180(2): 452-465.

Brundrett, M., Bougher, N., Dell, B., Grove, T. and Malajczuk, N. 1996. Working with Mycorrhizas in Forestry and Agriculture. ACIAR Monograph Issue 32: Canberra, Australia.

Brundrett, M., Melville, L. and Peterson, L. 1994. Practical methods in mycorrhiza research. University of Guelph, Guelph, ON, Canada: Mycologue Publications.

Camargo-Ricalde, S.L. and Dhilion, S.S. 2003. Endemic Mimosa species can serve as mycorrhizal "resource islands" within semiarid communities of the Tehuacán-CuicatlánValey, Mexico. Mycorrhiza 13: 129-136.

Clapp, J.P.,Young, J.P.W.,Merryweather, J.W . and Fitter, A.H.1995.Diversity of fungal symbionts in arbuscular mycorrhizae from a natural community. .New Phytologist 87:259265.

Clark, R.B. 1997. Arbuscular mycorrhizal adaptation, spore germination, root colonization, and host plant growth and mineral acquisition at low pH. Plant and Soil 192(1): 15-22.

Cuenca, G., De Andrade, Z. and Escalante, G. 1998. Arbuscular mycorrhizae in the rehabilitation of fragile degraded tropical lands. Biology and Fertility of soils 26: 107-111.

Daniell, T.J., Husband, R., Fitter, A.H. and Young, J.P.W. 2001. Molecular diversity of arbuscular mycorrhizal fungi colonizing arable crops. Ecology 36: 203-209.

Doran, J.W. and Zeiss, M.R. 2000. Soil health and sustainability: managing the biotic component of soil quality. Applied Soil Ecology 15(1): 311.

Douds, D.D. and Millner, P. 1999. Biodiversity of arbuscular mycorrhizal fungi in agroecosystems. Agriculture, Ecosystems and Environment 74:77-93.

Fisher, J.B. and Vovoides, A.P. 2004. Mycorrhizae are present in cycad roots. Botanical Reviews 70: $16-23$.

Harley, J.L. and Smith, S.E. 1983. Mycorrhizal Symbiosis. London and New York: Academic Press, pp. 483.

Harley, J.L. 1989. The significance of mycorrhiza. Mycology Research 92(2):129-139.

Helgason, T., Daniell, T.J., Husband, R., Fitter, A.H. and Young, J.P.W. 1998. Ploughing up the wood-wide web? Nature 394: 431-431.

Hu, Y., Rillig, M.C., Xiang, D., Hao, Z. and Chen, B. 2013. Changes of AM fungal abundance along environmental gradients in the arid and semi-arid grasslands of northern China. PLOS ONE 8: 1-10.

Janos, D.P. 1980. Vesicular-arbuscular mycorrhizae affect lowland tropical rainforest plant growth. Ecology 61:151-162.

Jeffries, P., Gianinazzi, S., Perotto, S., Turnau, K.K. and Barea, J.M. 2003. Contribution of arbuscular mycorrhizal fungi in sustainable maintenance of plant health and soil fertility. Biology and Fertility of Soils 37: 1-16.

Johnson, N.C., Pfleger, F.L., Crookston, R.K., Simmons, S.R. and Copeland, P.J. 1991. Vesicular-arbuscular mycorrhizas respond to corn and soybean cropping history. New Phytologist 117:657-663.

Kormanik, P.P. and McGraw, A.C. 1982. Quantification of vesicular-arbuscular mycorrhizae in plant roots. In Methods and principles of mycorrhizal research. Edited by 
N. C. Schenck. The American Phytopathological Society, St. Paul, MN. pp. $37-45$.

Koziol, L. and Bever, J.D. 2015. Mycorrhizal Response Trades off with Plant Growth Rate and Increases with Plant Successional Status. Ecology (In press).

Leake, J.R., Jhonson, D., Donnelley, D.P., Muckle, G., Boddy, L. and Read, D.J. 2004. Networks of power and influence: The role of mycorrhizal mycelium in controlling plant communities and agro ecosystem functioning. Canadian Journal of Botany 82(8): 1016-1045.

Lee, E.H., J.K. Eo, K.H. Ka and A.H. Eom 2013. Diversity of Arbuscular Mycorrhizal fungi and their roles in ecosystems. Mycobiology 41(3): 121-125.

Mapa, R.B., Somasiri, S. and Nagarajah, S. 1999. Soils of the Wet Zone of Sri Lanka; Morphology, Characterization and Classification. p.184 Soil Science Society of Sri Lanka. P.O. Box 10, Peradeniya.

Miller, R.M. 1987. Mycorrhizae and succession. Pages 205-219 in W. R. Jordan III, M. E. Gilpin \& J. D. Aber, (eds). Restoration ecology: a synthetic approach to ecological research. New York: Cambridge University Press.

Muthukumar, T., Sha, L.Q., Yang, X.D., Cao, M., Tang, J.W. and Zheng, Z. 2003. Distribution of roots and arbuscular mycorrhizal associations in tropical forest types of Xishuangbanna, southwest China. Applied Soil Ecology 22: 241-253.

Oehl, F., Laczko, E., Bogenrieder, A., Stahr, K., B€osch, R., van der Heijden, M. and Sieverding, E. 2010. Soil type and land use intensity determine the composition of arbuscular mycorrhizal fungal communities. Soil Biology and Biochemistry 42: 724-738.

Panabokke, C.R., 1996. Soil and agro-ecological environments of Sri Lanka. Natural Resources Series - No.2. Natural Resources, Energy and Science Authority of Sri Lanka. No. 47/5, Maitland Place, Colombo - 7, Sri Lanka.

Picone, C. 2000. Diversity and Abundance of Arbuscular Mycorrhizal Fungus Spores in Tropical Forest and Pasture. Biotropica 32(4a): 734-750.

Reeves, F.B., Wagner, D., Moorman, T. and Kiel, J. 1979. The role of endomycorrhizae in re vegetation practices in the semi-arid west. I. A comparison of incidence of mycorrhizae in severely disturbed vs. natural environments. American Journal of Botany 66: 6-13.

Reynolds, H.L., Packer, A., Bever, J.D. and Clay, K. 2003. Grassroots ecology: Plant -microbesoil interactions as drivers of plant community structure and dynamics. Ecology 84: 22812291.
Schultz, M., Arendholz, W.R. and Büdel, B. 2001. Origin and evolution of the lichenizedascomycete order Lichinales: monophyly and systematic relationships inferred from ascus, fruiting body and SSU rDNA evolution. Plant Biology 3:116-123.

Smith, S.E. and Read, D.J. 2008. Mycorrhizal symbiosis. San Diego, CA, USA: Academic Press.

Streitwolf-Engel, R., Boller, T., Wiemken, A. and Sanders, I.R. 1997. Clonal growth traits of two Prunella species are determined by cooccurring arbuscular mycorrhizal fungi from a calcareous grassland. Journal of Ecology 85: 181-191.

Thompson, I., Mackey, B., McNulty, S. and Mosseler, A. 2009. Forest Resilience, Biodiversity, and Climate Change. A Synthesis of the Biodiversity/Resilience/Stability Relationship in Forest Ecosystems. Technical Series no. 43. Secretariat of the Convention on Biological Diversity, Montreal.

Van der Heijden, M.G.A., Klironomos, J.N., Ursic, M., Moutoglis, P., Streitwolf-Engel, R., Boller, T., Wiemken, A. and Sanders, I.R. 1998. Mycorrhizal fungal diversity determines plant biodiversity, ecosystem variability and productivity. Nature 396: 69-72.

Warner, N.J., Allen, M.F. and MacMahon, J.A. 1987. Dispersal agents of vesicular-arbuscular mycorrhizal fungi in a disturbed arid ecosystem. Mycologia 79: 721 -730.

Wolfe, B.E. and Klinomus, J.N. 2005. Breaking new ground: Soil communities and exotic plants, Mycorrhiza 16: 299-363.

Yang, W., Zheng, Y., Gao, C., He, X., Ding, Q., Kim, Y., Rui, Y., Wang, S. and Guo, L. 2013. The arbuscular mycorrhizal fungal community response to warming and grazing differs between soil and roots on the Qinghai-Tibetan Plateau. PLOS ONE 8: 1-11.

Zangaro, W., Rostirola, L.V., de Souza, P.B., Alves, R.A., Lescano, L.E.A.M., Rondina, A.B.L., Nogueira, M.A. and Carrenho, R. 2013. Root colonization and spore abundance of arbuscular mycorrhizal fungi in distinct succesional stages from an Atlantic rainforest biome in southern Brazil. Mycorrhiza 23: 221-233. 